\title{
Quantitative Rice Postharvest Losses in the Albertine and Olweny Rice Hubs, Uganda
}

\author{
John Yawe, Alphonse Candia and Lawrence Grism Obeti \\ Agricultural Engineering and Appropriate Research Centre, Namalere \\ P.O Box 7144, Kampala, Uganda
}

\begin{abstract}
:
Since the introduction of rice in Uganda in 1904, insufficient information has been generated on quantitative rice postharvest losses in the country. Such inadequate information has partly constrained decision making in developing the rice industry in Uganda. The objective of this study was, therefore, to generate quantitative postharvest losses in two major rice growing hubs of Albertine and Olweny. The AfricaRice postharvest loss assessment procedure was used in the study during the growing seasons of 2015 and 2016. Data was collected at harvesting, threshing, drying and milling stages on 10 rice farms and 10 rice mills in each hub. The most grown "NERICA-4" and "Kaiso, K98" rice varieties both in Oryza Sativa group were used during the study in the Albertine and Olweny hubs respectively. The results indicated that total physical grain losses at aforementioned stages in Albertine and Olweny hubs were 16.8 and $14.1 \%$, respectively. This slight loss variation could be attributed to the different varieties and postharvest practices in these hubs. Losses at harvesting exhibited highest value 6.9 and $5.7 \%$ compared to threshing 4.7 and 4.8\%; drying 1.8 and 1.4\%; and milling 4.8 and 3.5\% for Albertine and Olweny hubs respectively. There was no significant difference $(\mathrm{p}>0.05)$ discerned in the losses between the hubs. Regardless of the rice hub, significant differences in loss levels $(p<0.05)$ existed along the postharvest operations. These results show that harvesting, threshing and milling were the critical control points in the management of quantitative rice postharvest losses in Uganda.
\end{abstract}

Key words: Oryza Sativa, threshing, milling, drying

\section{Introduction}

In quest to ensure food security and alleviate poverty, reduction of food postharvest losses becomes critical (Lipinski et al., 2013). Quantitative rice postharvest losses in sub Saharan Africa, range between $25.6 \%$ and $27.4 \%$ along the production chain (Affognon et al., 2015). The high postharvest losses have been attributed to poor post-harvest practices and use of inappropriate equipment (AfricaRice, 2012). Since the introduction of rice in Uganda in 1904 (Wilfred, 2006), not much has been done to comprehensively understand quantitative postharvest losses of rice in the country (Candia et al., 2012). The flaws in previous rice postharvest studies included lack of simple, adoptable and well-defined practical methodology to credibly quantify the physical losses as evidenced by wide variation in post-harvest loss results reported in literature (Affognon et al., 2015). In addition quantitative postharvest losses are dependent on location, postharvest stage, rice variety and postharvest practices. The study by Saunders et al. (1980) estimated that the total weight losses of rice in Uganda along the postharvest chain was $11 \%$. Candia et al. (2012) reported that the on-farm postharvest loss for Kaiso rice variety at harvesting, threshing, drying and cleaning operations in the eastern rice hub was $13.5 \%$. However, the wide variation in post-harvest loss results reported in literature has created incertitude in the methodologies of the researchers (Affognon et al., 2015). To address such gaps this study used a comprehensive AfricaRice (2012) postharvest loss analysis methodology to quantify and understand actual rice postharvest losses in Olweny and Albertine rice development hubs of Uganda. Generation of accurate information was very instrumental in determining the critical control points where efforts should be focused to control postharvest losses.

2.1 Scope of the study 
The study was conducted in Albertine and Olwenyi Rice hubs, located in the districts of Hoima and Lira, respectively (Figure 1). The hubs are among the three major rice growing hubs of Uganda. Hoima and Lira districts were selected because rice production, processing and marketing is highest in their respective hubs. Data was gathered at smallholder rice farms, farmers, cottage mills, millers and extension staff who were purposively selected from the mentioned districts. It was collected during 2015 and 2016 harvest seasons from a total of 20 farms in nine villages and 20 rice milling plants from eight towns spread across the two hubs. Specifically, data was collected at the four stages envisaged to be critical in postharvest value chain and included: harvesting, threshing, drying and milling.

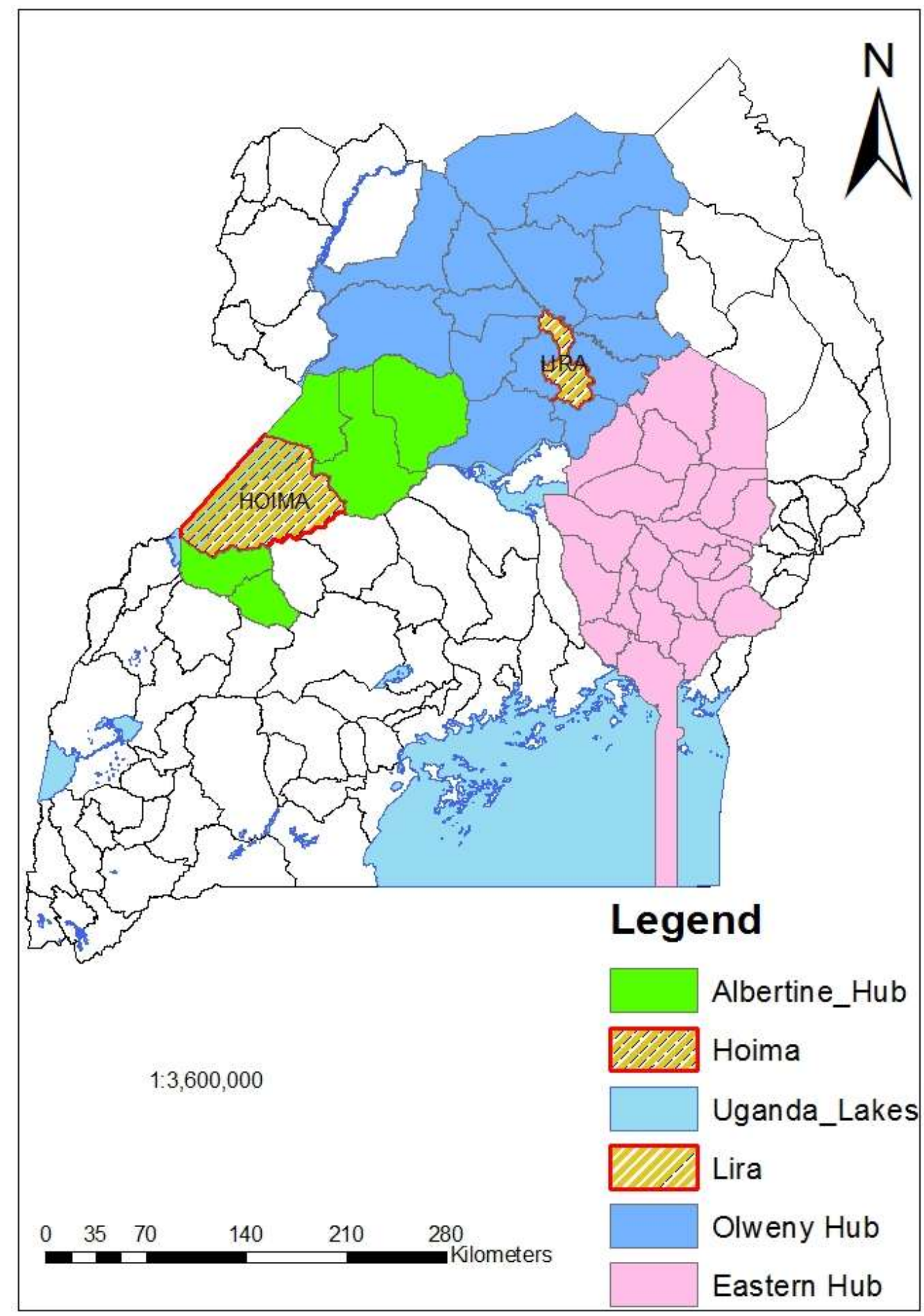

Figure 1: Map of Uganda showing study areas: Albertine and Olweny hubs

\subsection{Rice varieties used in the Study}


The study focused on two rice varieties; "NERICA-4 for Albertine hub" and "Kaiso, K98" for Olweny hub. The two varieties were selected on the basis, they were the most grown and traded varieties in the respective hubs. More so, these varieties have different characteristics given that the two hubs fall in different agroecological zones. "NERICA-4" is a rice variety grown mainly in upland while "Kaiso, K98" is a lowland variety

\subsection{Procedures for data collection}

The AfricaRice (2012) developed protocol for rice postharvest loss assessment was adapted and used to collect the data. Rural smallholder farmers and cottage rice millers were purposively sampled because of their important bearing in the rice production sector. As mentioned in section 2.1, the focus was on harvesting, threshing, drying and milling stages (Figure 2) of rice post-harvest handling operations. The data on physical losses were measured in the rice gardens and at cottage rice milling plants. The grain losses in the garden were determined on the same day when a farmer chose to harvest his/her rice, meanwhile, processing losses were determined during milling. The total physical quantitative losses were determined using equation 1.

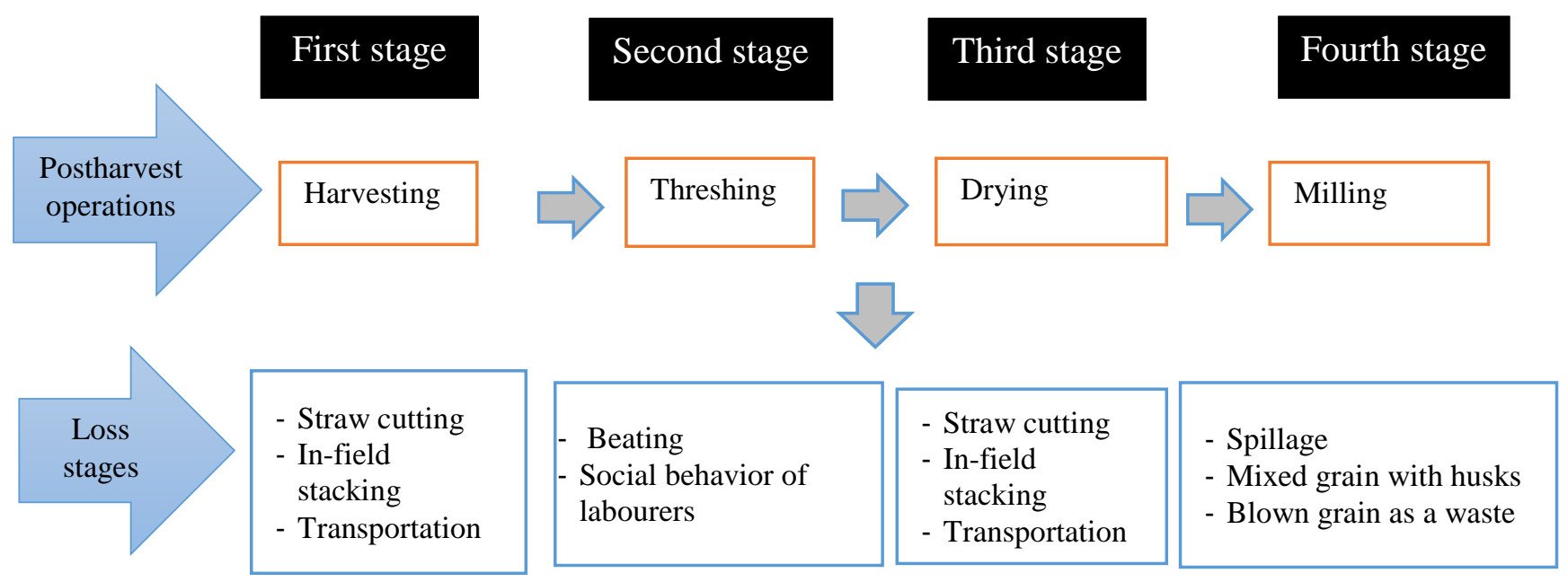

Figure 2: Schematic diagram showing stages where postharvest losses were determined

$$
W=\sum_{S=1}^{n} w_{s i}-------(1)
$$

Where

$W=$ Quantitative postharvest loss,

$S=$ Postharvest stage,

$w_{s i}=$ Weight loss per stage,

$n=$ Number of stages.

\subsubsection{Harvesting stage}

Harvesting loss is a result of traditional indifference, low level of technology and social behaviour of farm labourers involved in the work. Manual harvesting is the major practice used by smallholder farmers and it is accompanied with use of rudimentary tools particularly sickles and knives. Physical grain loss during the stage of harvesting occurred at three points: (1) cutting of the straws (2) intermediary piling (field-instacking) of the harvested straws and (3) transportation of the straws to a central threshing point. The total quantitative loss at harvesting was therefore given by summation of losses at these three sub-stages as shown in equation 2 .

$$
w_{s_{1}}=w_{s_{h}}+w_{s_{p}}+w_{s_{t}}-------(2)
$$

Where

$w_{s_{1}}=$ Total quantitative loss at production stage, 
$w_{s_{h}}=$ Grain loss during cutting of straws (shattering loss),

$w_{s_{p}}=$ Grain loss due to pilling of harvested straws,

$w_{s t}=$ Grain loss due to transportation of harvested straws to the focal threshing point

\section{Grain losses during straw cutting (shattering)}

Together with a farmer and/or farm labourers, a plot of size $1.5 \times 1.5 \mathrm{~m}$ was marked. The marked plot was harvested in customary manner by the farm labourers and the harvested straws were piled on a provided tarpaulin. All the paddy that dropped in the marked plot were immediately handpicked and weighed using a pocket digital weighing scale of capacity $500 \mathrm{~g}$ and $\pm 0.001 \mathrm{~g}$ accuracy. The grains on the piled straws were thoroughly and carefully threshed, cleaned and weighed. The plot yield was then estimated by adding this weight of grain to the weight of dropped grains. The losses were calculated by expressing weight of dropped grains as a percentage of the marked plot yield. As the moisture content has an effect on timing of the harvests, it was measured using a digital multi-grain moisture tester, Riceter model m401made by Kettelectric Company, Japan. The procedure was repeated in three locations of the same paddy field. Average loss was taken as the grain loss during cutting of the straws.

\section{Grain losses due to intermediary piling (in-field stacking)}

Plot size of $5 \times 5 \mathrm{~m}$ was marked in triplicate on the same paddy field where grain loss due to cutting was determined. In this case, two tarpaulins were allocated for each plot. During harvesting of each plot, the straws were slowly and carefully cut, and placed on the first tarpaulin. After harvesting the plot, all the stalks were carefully transferred onto second tarpaulin for observing whether any grains dropped on the first tarpaulin. The grains that dropped on the first tarpaulin were collected, cleaned, weighed and recorded separately. These grains were taken as loss due to in-field stacking. The grains on the second tarpaulin were then thoroughly threshed, cleaned, and weighed. The plot yield was determined by adding the weights of grain on both first and second tarpaulins. Due the nature of cutting the straws, it was assumed that grain loss due to cutting was very negligible. The grain loss due to in-filed stacking was estimated by expressing the weight of grain dropped on the first tarpaulin as a percentage of the plot yield. Average grain loss from the three plots was considered as the grain loss due to in-field stacking.

\section{Grain losses during transportation of harvested straws}

The losses during transportation on each farm were determined from three plots each measuring $5 \mathrm{x} 5 \mathrm{~m}$. To collect dropped grains during transportation, two tarpaulins were placed; one for placing the harvested rice straws and was put near the plot. The latter was put at a distance on a clear raised ground were threshing was carried out. The marked plots were carefully harvested using sickles. The harvested stalks were placed on a tarpaulin as the harvesting operation continued. The initial weight of the piled rice stalks in bundles was determined using a spring balance. Afterwards farm labourers transported these bundles to the threshing site as it is commonly done. Upon reaching the threshing point (second tarpaulin), the rice bundles were immediately re-weighed using the same weighing scale and recorded. The weight of grain lost in each bundle was calculated by subtracting the second weighed value from the initial. The transportation loss in each plot was calculated by adding the grain losses from each bundle. Thereafter, all the rice on each bundle was carefully threshed, cleaned and weighed to give weight of grain that remained on the bundles. This weight was added to transportation loss to give the plot yield. The transportation loss was then expressed as a percentage of plot yield. Grain loss due to transportation of harvested straws to central threshing point was given by average of the transportation losses from the three plots.

\subsubsection{Threshing stage}

At this stage quantitative losses was defined as the scattered grain which could not be collected during threshing and the un-threshed grain remaining on stalks after threshing. The experiment focused on establishing losses during the manual threshing (beating method) which is used by more than $88.9 \%$ of the farmers in Uganda (Candia et al., 2012). The threshing loss determined was due to two factors: social 
behaviour of workers and beating method. The total grain loss during traditional threshing was therefore given by the sum of grain losses due to these two factors.

Losses due to social behaviour of labourers

Bad behaviour of labourers during threshing of rice has been a problem for rice farmers in Uganda. The labourers purposely don't thresh the grain completely with the aim of re-threshing the threshed straws in the absence of the farmer to glean the remaining grain for personal benefit. Since the labourers are a part of the community, such a grain is not necessarily considered as a loss to the local economy. However this is considered as a loss to farmer who toiled to produce it. It should also be noted that by the time, labourers return to glean the unthreshed grain, it has already been contaminated by carcinogenic aflatoxins. Economic value of the gleaned grain is far less than the cost of treating the acquired cancer. Ultimately the gleaned grain by labourers, which is usually after two to three days of threshing is still a loss to the community. The grain loss through the social behaviour was determined through administering a semi-structured questionnaire to a total of 20 farmers and 8 extension officers. The respondents estimated the incomplete threshing in $\mathrm{kg}$ corresponding to the yield of the garden.

\section{Grain loss due to traditional beating method}

The threshing was carried out immediately after harvesting of rice. In this case, three sample plots of $10 \mathrm{~m} \mathrm{x}$ $10 \mathrm{~m}$ were marked out in the paddy field ready for harvesting. In order to minimize grain shattering, all the rice in the plot was carefully harvested by farm laborers using sickles. The harvested stalks were collected and heaped in the center of the farmer's threshing tarpaulin. The farmer's tarpaulin was also made to sit on a big undamaged tarpaulin measuring $5 \times 6 \mathrm{~m}$ to cater for grains lost due to torn farmer's tarpaulins. Additional tarpaulins were placed all round to trap any scattered grain during threshing. Farmers and labors were allowed to thresh these samples in the traditional way of beating using sticks. All those straws which were not completely threshed were sorted and re-threshed by hand stripping to remove any remaining grains on straws. The resulting grain was cleaned, weight taken and recorded as grain lost due to incomplete threshing. Similarly the scattered grains on tarpaulins were collected, cleaned, weighed and recorded as grain lost due to scattering. The main threshed grain by beating was also cleaned, and its weight and moisture content measured. The plot yield was obtained by adding these weights of grain lost due to incomplete threshing and scattering, and the main grain. The steps were repeated for two more replications in the same paddy field. The grain loss during manual threshing was computed from equation 3 and expressed as a percentage of plot yield.

$$
w_{s_{2}}=w_{s_{c}}+w_{s_{u}}-----(3)
$$

Where

$w_{s_{2}}=$ Total quantitative loss due to threshing,

$w_{s_{c}}=$ Grain loss due to scattering,

$w_{s_{u}}=$ Grain loss due to un-threshed grains remaining among stalks

\subsubsection{Sun drying}

Most smallholder rice farmers in Uganda have adopted tarpaulin as the main drying structure for dehydrating paddy in sunshine. It was then used as the drying structure in this study. These smallholder farmers usually carry out the drying and cleaning operations simultaneously. At the end of drying day, farm labourers carry out cleaning and the process is repeated until the paddy attains the storage moisture content. Similar to threshing operation, farmers experience grain losses due to bad behaviour of labourers during cleaning process. The grain loss during drying in sunshine was then given by the sum of losses due to use of drying structure and social behaviour of labourers during cleaning of grain.

The grain loss during drying was determined by setting experiments of drying paddy on tarpaulins at 10 different farms in each hub. Farmers were then allowed to dry the rice in the customary way. Grain loss included grains that fell along the tarpaulin edge and those that dropped throw holes in the tarpaulin. At the end of every drying day, these grains were collected, kept and dried separately to storage moisture content of 
$12 \%$. The daily collected grains for each experiment were added together after attainment of storage moisture content and the weight obtained was taken as the quantity of grain lost during the drying process. Percentage of grain lost was determined by dividing quantity of grain lost during the drying process by the total weight of the dried grain. Total weight of the dried grain was the sum of grain lost during the drying and what the farmer considered as his/her main dried grain. The procedures were repeated for the subsequent nine farms. The representative physical grain loss during sun drying was given by the average value of the drying losses from the 10 farms.

Participatory research technique based on interactive face to face interview was used to collect data on grain loss during cleaning operation. The respondents included eight farmers, eight women who do cleaning and three extension officers in each hub. The respondents were tasked to estimate the grain lost during cleaning five bags of paddy. The estimated weight from each respondent was then expressed as a percentage of total weight of the paddy in five bags. The average of the percentage lost was obtained to give representative grain lost due to the traditional method of winnowing during paddy cleaning.

\subsubsection{Milling stage}

Nearly $95 \%$ of the total paddy produced in Uganda is milled by the cottage rice milling plants using improved englebergs and Mill-top series especially SB 30 and 50 (Candia et al., 2008). Physical grain loss was therefore determined at the cottage rice milling plants through conducting experiments using five improved engleberg and five mill-top types of rice mills owned and operated by different rice mill managers in each of the two hubs. During the study, focus was laid to estimate losses due to spillage, grains mixed with husk or bran and grain blown out together with chaff. Total quantitative grain loss at engleberg rice mill was given by equation 4 and that for milt-top given by equation 5 .

$$
w_{s_{3}}=w_{s_{s}}+w_{s_{r}}------(4)
$$

Where

$w_{s_{3}}=$ Total quantitative loss during milling,

$w_{s_{s}}=$ Loss due to grain spillage,

$w_{s_{r}}=$ Loss due to milled grains mixed with bran,

$$
w_{s_{3}}=w_{s_{s}}+w_{s_{r}}+w_{s_{b}}----(5)
$$

Where

$\mathcal{W}_{s_{3}}=$ Total quantitative loss during milling,

$w_{s_{s}}=$ Loss due to grain spillage,

$w_{s_{r}}=$ Loss due to milled grains mixed with bran,

$w_{s b}=$ Loss due to grain blown out with husk and chaff as waste by fan

In each experiment the rice mill and its surrounding was thoroughly cleaned. Thereafter tarpaulins were arranged to collect all the grain that scattered and dropped during milling, collect rice husk and rice huskbran mixture from the different outlets. During each experiment at the individual mills, rice mill operators milled 100kg of paddy in their usual practice. All the scattered and dropped grains were collected, cleaned, weighed and recorded as grain loss due to spillage. The entire husk-bran mixture was collected and winnowed. Weight of the recovered grain taken and recorded as grain loss through bran-husk mixture. 
Lastly, the husk-chaff mixture was collected and winnowed. Weight of the recovered grain was also taken and recorded as grain loss due to fan pressure.

\section{Data analysis}

Data analysis was divided into two parts. The first part employed the use of descriptive statistics to describe means of grain losses within the individual postharvest operations. The second part involved application of two experimental designs. The first experimental design, a 2 X 2 CBD was used to compare the means of grain losses across the two rice hubs and varieties. Rice development hubs (2 treatments: Albertine and Olweny)) and varieties ( 2 treatments: NERICA 4 and Kaiso, K98) were the two independent factors that influenced grain losses across the two locations. NERICA 4 and Kaiso, K98 were the rice varieties used during this study in Albertine and Olweny hubs respectively. Two-way ANOVA, LSD method was used in analysing the data from this experimental design. The second experimental design was to compare means of grain losses along the different postharvest operations within a hub. This design had postharvest operations as the only independent factor and had 4 treatments: harvesting, threshing, drying and milling. One-way ANOVA, LSD method was used to compare the means of grain losses along these treatments. SPSS version 16.0 and MS Excel Computer Soft-wares supported the data analysis and processing.

\subsection{Results and Discussions}

\subsection{Harvesting grain losses}

The grain physical loss obtained at harvesting stage was due to grain shattering during cutting of straws, infield-stacking of the harvested straws and transportation of the straws to a central threshing point and the investigated results are shown in Figure 3. The results showed that physical grain loss at harvesting stage in the two hubs was still high ranging between $6.93 \pm 1.79 \%$ and $5.68 \pm 2.01 \%$ for Albertine and Olweny hubs respectively. The losses due to shattering had the lowest values while in-field-stacking registered the highest amount.

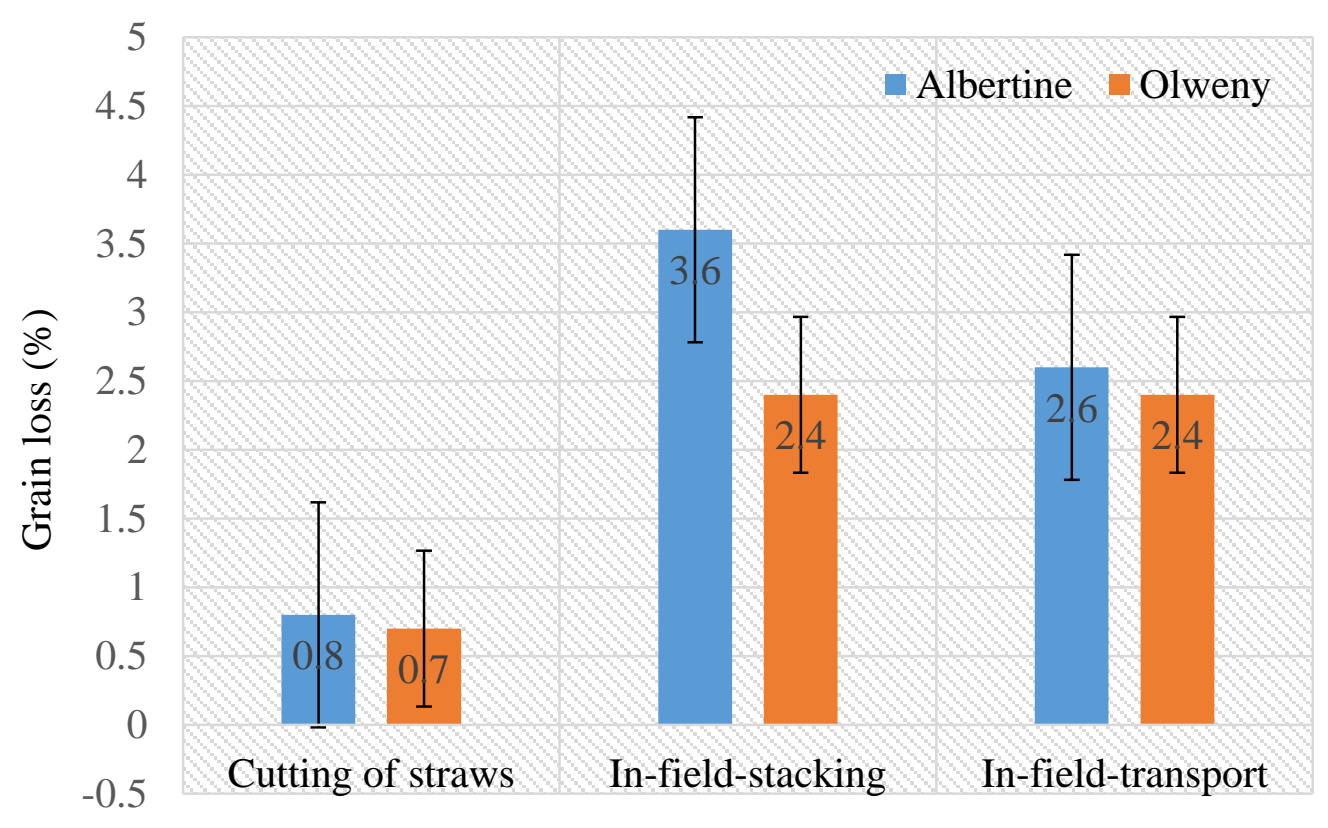

Harvesting sub-stage operations

Figure 3: Grain losses at harvesting stage

The grain losses due to in-field-stacking were almost the same as values earlier obtained by Candia et al. (2012) in the Eastern hub of rice development. By contrast, results due to shattering in this study indicated lower values. The newly generated lower levels could have been attributed to farmers harvesting their paddy at the correct harvesting time and during good weather conditions. There was no significant difference ( $>0.05)$ in harvesting losses between the rice hubs. Regardless of the Rice hub, significant differences $(p<0.05)$ existed between sub-stages of harvesting. Although statistically there was no difference in grain 
loss at these two hubs, Albertine had still higher grain loss (7\%) than Olweny hub (5.5\%). Grain moisture content is a critical factor in influencing shattering. The results indicated that the mean moisture content of paddy at harvesting in Albertine and Olweny hubs were 20.43 and 23.79\% (w.b.) respectively. The moisture content of paddy in Albertine is slightly below the recommended lower limit of $22 \%$ for harvesting. Considering the very low shattering properties of NERICA 4 variety, the high grain loss at harvesting stage in Albertine hub could be attributed to hot weather conditions during the harvesting time (November December) in this region. The hot weather makes the grain lose moisture much faster than expected. This accelerates grain shattering and hence high levels of grain losses. In comparison to similar studies elsewhere, the total harvesting losses due the same harvesting technologies correlated very well with those obtained in Ghana which ranged between 4.07 and 12.05\% (Appiah et al., 2011)

\subsection{Threshing losses}

The grain losses at threshing stage consisted of losses due to incomplete removal of grains from the ears of the rice straw pinnacles, scattering of grain because of the impact force from beating stick and social behaviour of hired labourers. The study results showed that grain losses were 5.48 and 5.69\% during threshing by beating method in Albertine and Olweny hubs respectively. These results were consistent to those reported by Candia et al. (2012) for Eastern hub (3.1 - 6.4\%) and Appiah et al (2011) for Ghana (3.94 $-6.96 \%)$. Although rice varieties grown in the two hubs were different, no significant difference $(\mathrm{p}>0.05)$ was discerned in the losses between the hubs (Figure 4).

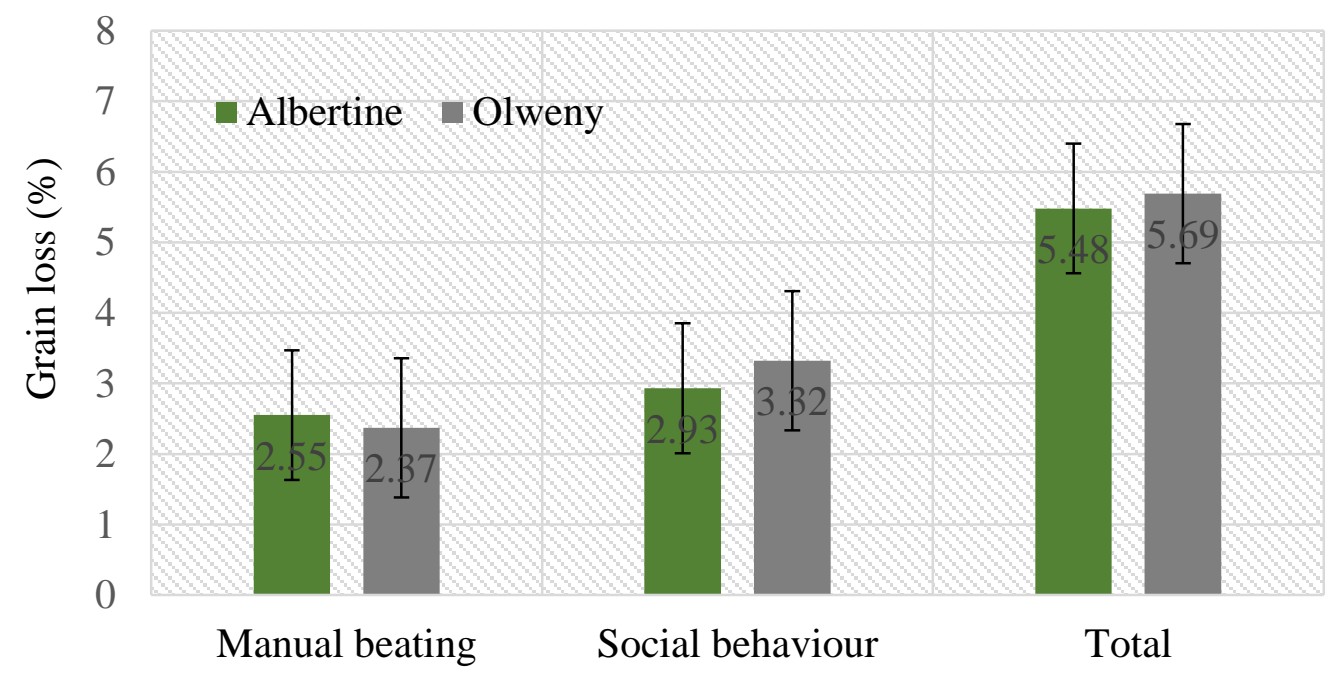

Stages at which threshing loss occurs

Figure 4: Grain losses, during manual threshing

\subsection{Grain losses during Drying}

Grain losses during drying was given by the sum of grain that dropped and those lost due to bad behaviour of labourers in the cleaning process. The results obtained are presented in Figure 5. The average grain loss through dropping in Albertine and Olweny hubs were 0.50 and $0.10 \%$, respectively. The evident lower value of dropped grain obtained in Olweny as compared to Albertine could be attributed to farmers in Olweny rendering high level of care to rice. It was interestingly observed that farmers in Olweny suffered from grain loss $(1.33 \%)$ through social behaviour more than their counterparts in Albertine. This could be explained by massive use of labourers in Olweny as compared to Albertine where farmers mainly depend on family labour to carry out drying and cleaning. 


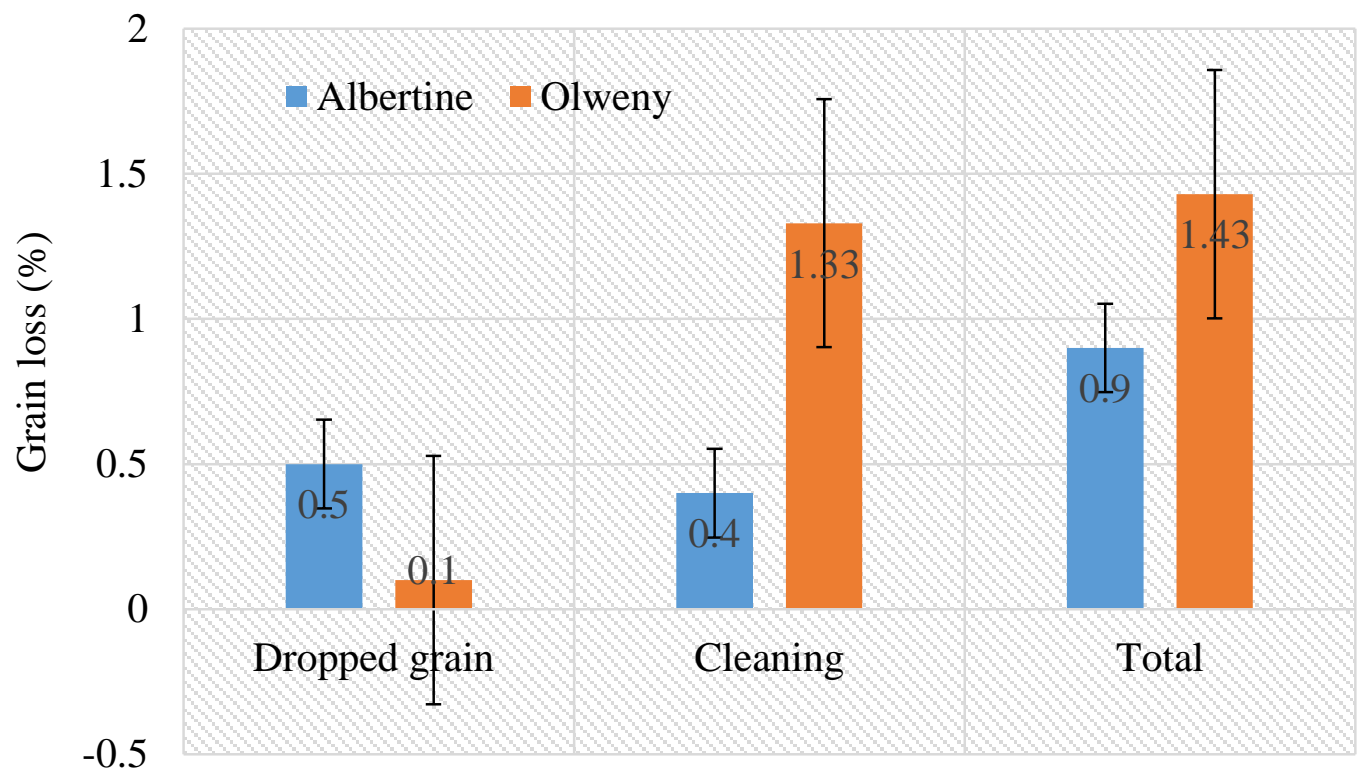

Stages where grain loss occured

Figure 5: Grain losses at drying operation

\subsection{Milling grain losses}

Results obtained from milling experiments are shown in Figure 6. The results indicated that the total grain losses from the two types of mills to the economy in the Albertine hub were significantly $(\mathrm{p}<0.05)$ higher than in Olweny hub. The high losses in the Albertine milling plants were attributed to the fact that the millers in this hub have less technical knowledge in rice milling and less experience on the job compared to their counterparts in the Olweny hub. Results presented in Figure 6 also point out that improved Engleberg rice mills cause slightly more physical grain loss (4.8\%) than the Miltop mills (4.03\%).

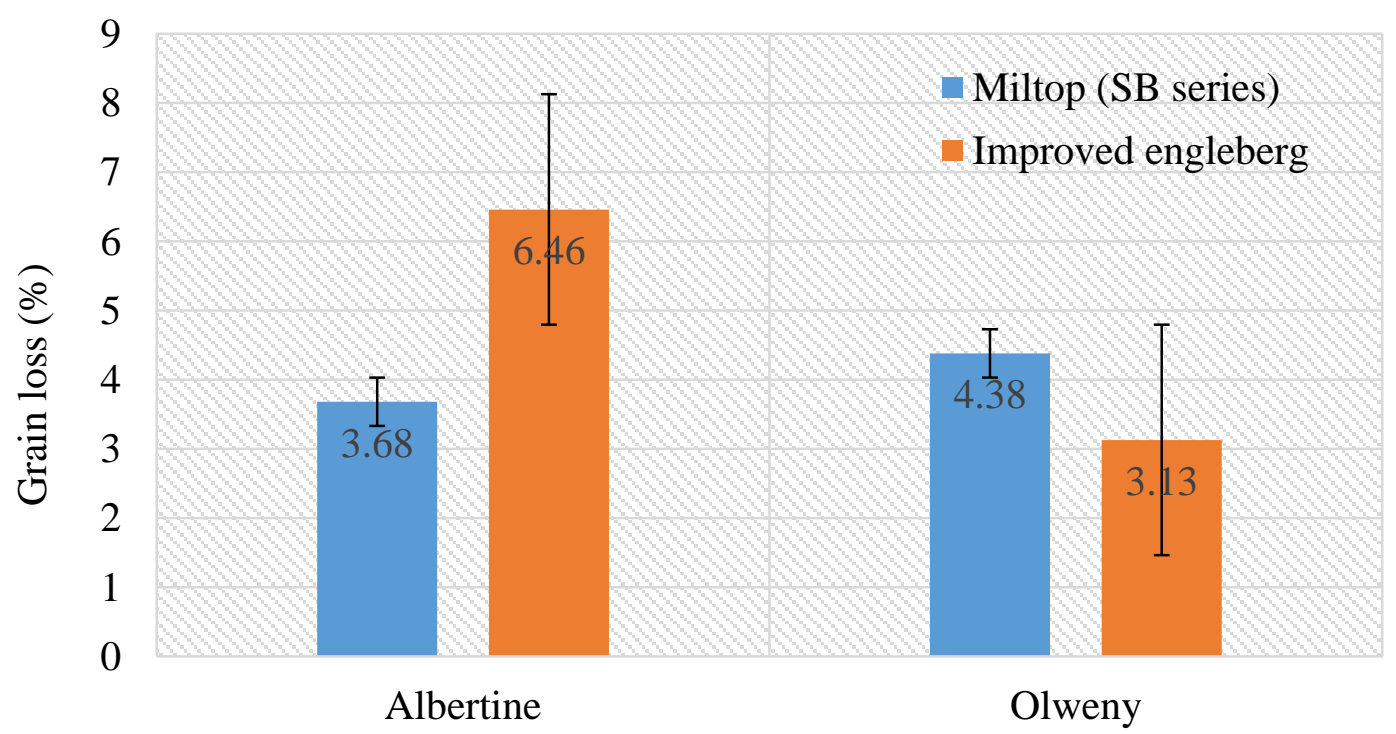

Rice development hubs

Figure 6: Percentage of grain loss at mill cottage

\section{Conclusions and recommendations}

The total physical grain loss at the different hubs was $16.8 \%$ and $14.1 \%$ in Albertine and Olweny respectively. On average physical rice grain loss in the study hubs was $15.45 \%$. Further, post-harvest operations viz. harvesting, milling and threshing were the critical control points in the management of quantitative rice postharvest losses in Albertine and Olweny hubs. The obtained loss values are highly 
significant not only of their adverse economic impact, but equally threatens food security to farming families. To achieve successful maximal loss reduction, the promotion of specific technologies focusing on on-farm improvement should be established and there should be provision of the technical support to the farmers along the different postharvest stages. Investments in further research aimed at developing costeffective and appropriate technologies can provide momentous gains in the effort to reduce these losses at farm level.

\section{Acknowledgement}

The authors are indebted to Global Affairs Canada (GAC) for funding this research through Grant no. A034968 and AfricaRice for technical support. The authors would like to express their sincere gratitude to rice farmers and millers who voluntarily provided their facilities for use in this study.

\section{References}

[1] Affognon, H., Mutungi, C., Sanginga, P. \& Borgemeister, C. 2015. Unpacking Postharvest Losses In Sub-Saharan Africa: A Meta-Analysis. World Development, 66, 49-68.

[2] AFRICARICE 2012. Manual For Assessment Of Post Harvest Losses In Rice. Manual For Assessment Of Post Harvest Losses In Rice

[3] Appiah, F., Guisse, R. \& Dartey, P. 2011. Post Harvest Losses Of Rice From Harvesting To Milling In Ghana. Journal Of Stored Products And Postharvest Research, 2, 64-71.

[4] Candia, A., Okurut, S., Komaketch, A., Saasa, A. \& Mudusu, J. 2012. On-Farm Post-Harvest Physical Grain Losses Of Â€ E Kaiso Â€ Rice Variety In Eastern Uganda. Uganda Journal Of Agricultural Sciences, 13, 61-70.

[5] Lipinski, B., Hanson, C., Lomax, J., Kitinoja, L., Waite, R. \& Searchinger, T. 2013. Reducing Food Loss And Waste. World Resources Institute Working Paper, June.

[6] Saunders, R., Mossman, A., Wasserman, T. \& Beagle, B. 1980. Rice Postharvest Losses In Developing Countries. US Department Of Agriculture Science And Education Administration. Agricultural Reviews And Manuals, 9.

[7] Wilfred, O. R. 2006. Final Survey Report On The Status Of Rice Production, Processing And Marketing In Uganda. A Report Submitted To The Embassy Of Japan In Uganda Through JICA And Sasakawa Africa Association-Uganda, Kampala. 